\title{
Estructura y dinámica de la conciencia moral en el proceso educativo
}

\author{
JOAN CARLES MÉLICH \\ Universidad Autónoma de Barcelona
}

\begin{abstract}
SUMMARY.-The aim of this work settles on describing, through the fenomenological methodology, the structure and dinamics of the moral conscience and its function in the educational process.

The moral conscience, equally than the epistemological moral, is endowed of a temporary structure. Time, through its three dimensions (past, present, and future) allows the dialectics of the moral conscience. In the past the values are settled, in the present takes place the hermeneutics of reality, and in the future make an irruption the duty and the project.

In the second part of this article, the author gets the moral conscience with the educational conscience together (in touch). Both are not identic, one cannot be reduced to the other. The main (basic) diference settles on the «technical question (matter)». Hence the educational conscience does not limit itself; like the moral one, to a hermeneutics of the present, but moreover it provokes and endeavours an «intervention» of the present, that is to say, a modification of the world.
\end{abstract}

El hombre es el animal que pregunta. El preguntar no es un modo de ser, entre otros, sino el modo de ser propio de la realidad humana. El ser que pregunta «existe». La diferencia esencial entre existir y ser radica en la capacidad de preguntar.

No cabe formular ninguna pregunta sin referirnos a aquella capacidad ontológica que la hace posible: la conciencia. Si abro interrogantes es porque preexiste en mi una realidad apta para ello. Se trata entonces de elucidar qué es eso que llamamos conciencia. Para ello utilizamos de modo sui generis el método fenomenológico.

\section{EL «TIEMPO» COMO ESTRUCTURA Y DINÁMICA DE LA CONCIENCIA MORAL}

La conciencia posee «dos caras», y ambas se constituyen temporalmente. La «conciencia epistemológica» (Bewußtsein) y la «conciencia moral» (Gewissen) resultan esas dos realidades que configuran el eidos del fenómeno consciente.

La tradición fenomenológica clásica se ha ocupado mucho más de la primera; desde nuestro particular interés, empero, debemos introducirnos en los difíciles sen- 
deros de la segunda por considerar que es ésta la que hace comprensible el fenómeno educativo. Así observaremos que sólo tiene lugar el proceso pedagógico si se fundamenta en el tiempo de la conciencia moral. Pero advertimos: tal base temporal no es ni social, ni biológica, ni psicológica, sino ontológica; aunque ello no significa que no deban considerarse estas otras dimensiones.

La conciencia moral no se puede constituir al margen de un absoluto. Pero lo dramático está vigente desde la «muerte de Dios» anunciada por el «superhombre» (Uebermensch) de Nietzsche. Leída ésta en la línea heideggeriana de Holzwege (Heidegger, 1980:205-263) significa la muerte de todo «absoluto» y, en consecuencia, de todo punto de referencia para la conciencia moral. En pura lógica, si no hay absoluto todo es relativo, y si todo es relativo ¿qué sucede con la moral? El absoluto, de existir, se hallaría fuera del tiempo. La conciencia moral, entonces, sólo descubriría su fundamento (Grund) en una opción teórica por este absoluto. Este jamás podría alcanzarse ni poseerse, tan solo vislumbrarse, tenerlo como «horizonte» precario. Sin embargo, la opción por el absoluto no da solución a la cuestión de los contenidos de los imperativos morales. El absoluto nos dicta la obligatoriedad de la acción moral, pero jamás los contenidos de tal obligatoriedad. Sin el absoluto, está claro, la conciencia moral se nos queda sin obligación. Pero ¿cómo resolver la tragedia del contenido de la obligación ética? Desde el punto de vista de la fenomenología en su vertiente «existencial» sostenemos que no nos está permitido acceder racionalmente a los contenidos de los imperativos morales.

Nos encontramos ante una opción vital, pasional. No podemos, entonces detenernos ante este callejón sin salida. Es propio del «tiempo de crisis» axiológica mostrar la imposibilidad de decidir la estructura material del deber moral categóricamente.

$\mathrm{Si}$ seguimos nuestra peregrinación fenomenológica desvelamos unos nuevos elementos que configuran la estructura de la conciencia moral (Gewissen) que se nos antojan imposible de «colocar entre paréntesis»; a saber: los valores, la realidad $y$ el deber.

Este triángulo propio de la conciencia moral deberá construirse y constituirse temporalmente. El tiempo es el vertebrador de los valores adquiridos a través de la tradición y de la educación. Estos se instalan en el «ek-stasis» del pasado. El presente edifica la realidad, el mundo, y el futuro hace lo propio con el deber.

La conciencia nos permite enjuiciar el «aquí» y al «ahora» (Dervolav, 1989), el presente, la realidad, el mundo en el que me encuentro «arrojado», el «estado de yecto», por utilizar un término heideggeriano (Heidegger, 1979, 175-180), desde unos valores que ella ha tomado sobre sí en el «ek-stasis» del pasado. Es este el instante en que la conciencia moral me lanza hacia el deber - futuro- que implica un «llegar a ser» (werden) y, por lo mismo, un «no-ser-aún» (noch nicht).

La dinámica que caracteriza la actividad de la conciencia moral es dialéctica, agónica y trágica. La relación entre los tres «ek-stasis» de la temporalidad resulta armónica y, al mismo tiempo, dramática. Los tres se complementan; sin embargo, de acuerdo con la fenomenología de Husserl y Heidegger, admitimos que existe un primado del futuro como «ek-stasis» propio de la conciencia moral.

Esto no significa que el pasado y el presente no se mantengan vivos en el proceso intencional de futurización de la conciencia moral, que no es otro que el deber; 
bien al contrario. Tomemos el texto de Husserl en el que compara la temporalidad de la conciencia con una «melodía». Así:

«Al resonar el nuevo sonido, no ha desaparecido el anterior sin dejar ninguna huella, pues, en este caso, seríamos incapaces de notar las relaciones de los sonidos subsiguientes; tendríamos en cada momento un sólo sonido y, dado el caso, en el intervalo entre dos sonidos una fase vacía, pero nunca la representación de una melodía. «(Husserl, 1959, 57).

Hallamos en la conciencia moral (Gewissen) la intencionalidad de la conciencia epistemológica (Bewußtsein) propuesta por Brentano en una doble dimensión; a saber:

a) En la medida en que la conciencia moral es crítica y enjuiciadora de la realidad, del mundo. Su ser-en-el-mundo jamás puede resultar, ante la mirada de la conciencia moral, un ser pacífico, sino radicalmente censor.

b) Desde el preciso instante que se lanza hacia un porvenir, probablemente ausente de límite. Es el deber. Un «futuro» que, como el éros socrático, no podrá satisfacerse. De ahí que toda conciencia moral sea, en último término, una conciencia utópica.

\section{El pasado}

La herencia del pasado que la conciencia ha tomado sobre sí misma constituye el paradigma desde el que interpretamos el presente mundano y futurizamos el deber moral.

La irrupción, empero, del tiempo de crisis axiológico, ha difuminado las fronteras entre responsabilidad e irresponsabilidad (Lassahn, 1989, 386); o lo que es lo mismo: la pérdida de un «referente compartido» entre los miembros de una misma colectividad.

La educación moral actual se halla ante este grave escollo sin tener medios para poder superarlo. Sin embargo no se han hecho esperar alternativas: desde la defensa de una «aparente» neutralidad (Sarramona, 1990,70), al dogmatismo más visceral, en un intento, éste, de recuperar la unidad cosmovisional perdida y superar el tiempo de crisis.

No existen el presente ni el futuro sin el punto de partida que nos otorga el pasado. Jamás puede tener lugar una hermenéutica del mundo — presente-, como tampoco la propuesta de un deber - futuro-, sin el Grund ético que nos proporcionan los valores - pasado-.

La conciencia moral, a diferencia de la opción sartriana, no es una «nada-deser», sino que vive enraizada en los valores, en la «facticidad paradigmática» que le otorga el pretérito. No creo que tal aserto atente contra el postulado fenomenológico de la intencionalidad de la conciencia, antes al contrario, lo hace más real, más «creíble».

La educación, entonces, es el vínculo que hace posible que la conciencia moral integre como su fundamento los valores familiares, sociales, y sobre todo, éticos. Desde tal punto de vista, el «valor» es entendido como un «punto de referencia», bien real o ideal, que tomamos como «modelo» (paradigma) para abordar la hermenéutica del presente, del mundo. La «integración» de los valores por parte de la con- 
ciencia moral no debe concebirse desde el punto de vista estático, sino desde el dinámico. Queremos decir: el pasado no queda asimilado sin más por la conciencia, sino que ésta por su propia dialéctica es capaz de evaluar constantemente sus valores desde el presente y el futuro.

Por otro lado, tampoco afecta, contrariamente también a lo descrito por Sartre, a la libertad, de la conciencia. La relación «agónica» entre los distintos «ek-stasis» de la temporalidad hacen posible una libertad «existencial» y no ilusoria. El adoctrinamiento (Reboul, 1981) es el enemigo más feroz de la conciencia moral.

\section{El presente}

Toda actividad de la conciencia moral está comprometida con la realidad desde el preciso instante que hunde sus raíces en la facticidad del espacio constituido. La conciencia es tiempo, no posee extensión, pero esto no significa que queda liberada del espacio. Tampoco debe entenderse éste como un factum, sino como un «constituirse» dinámicamente comprometido con la temporalidad de la conciencia. En tanto que presente, la conciencia se convierte en una «hermenéutica del espacio», de la realidad dada.

Todo acto de conocimiento - ahí coinciden la conciencia epistemológica y la conciencia moral- supone una interpretación del correlato noemático de la conciencia. La novedad que aporta la conciencia moral resulta ser, por de pronto, arrancar desde un a priori axiológico-moral (instalado en el pasado) y, a continuación, un futuro (deber). Pero por su misma naturaleza de primacía del futuro, la conciencia moral está arraigada en el presente, aunque este compromiso no le impide su capacidad de distanciamiento - característica ontológica de toda conciencia-, sino todo lo contrario. La «crisis» debe estallar en la misma acción hermenéutica de la realidad.

Aquí también juegan una función esencial las relaciones educativas. Aprender a ver, a valorar, a juzgar, a criticar, a construir... son elementos esenciales a desarrollar en el educando si no se quiere atentar contra su «ser-si-mismo» (Selbstein). Se impone, entonces, la necesidad del educador para que colabore con el educando en la configuración de su contacto con el presente, la realidad, el mundo. La «crisis» no debe entenderse únicamente en el sentido de «finalidad» de la educación — puesto que en tal caso pertenecería al ámbito del futuro-, sino también como «medio», como «actualidad», como «presente». Educar no sólo «para» la crítica, sino «en» la crítica, se nos antoja de suma importancia.

\section{El futuro}

El futuro es el «ek-stasis» fundamental y originario de la conciencia moral. Como advierte Heidegger en Der Ursprung des Kunstwekes, «origen» (Ursprung) significa aquello a partir de lo cual y gracias a lo cual una cosa (sache) es aquello que es, y cómo es; en otras palabras: su esencia (Wesen) (Heidegger, 1980, 7).

El futuro es el «origen» de la temporalidad de la conciencia, aunque esto no significa, que pueda subsistir de modo independiente a los otros «ek-stasis». 
Así es el futuro el que hace posible que la conciencia pueda constituirse como «existencia» («ek-sistencia»). Veámoslo en un texto de Was ist Metaphysik? del propio Heidegger:

«Solamente el hombre existe. La roca es, pero no existe. El árbol es, pero no existe. El caballo es, pero no existe. El ángel es, pero no existe. Dios es, pero no existe.» (Heidegger, 1978,370).

La capacidad de «pre-venir» es lo que caracteriza a la «existencia». La realidad humana no se limita a vivir ni su historia, ni su mundo sino que sobre todo los hace, los fabrica, los crea (Danner, 1979, 20). Todo existir es llegar a ser y, por lo mismo, un «no-ser-aún», un noch nicht (Heidegger, 1979). Pero la conciencia que hace posible esa capacidad de futurización no se sostiene aquí en un sujeto trascendental, como en Kant o en Husserl, ni en una «nada de ser», como en Sartre, sino en el sujeto personalizado, único e irrepetible: la «existencia». Esto es así precisamente porque el sujeto trascendental jamás puede ser «ético». Siguiendo a Lévinas, argumentamos que tal sujeto no tiene «rostro», y además corre el riesgo de ser «solipsista», como se desprende de la quinta «meditación cartesiana» de Husserl (Husserl, 1977).

Ambos aspectos (el rostro y la interacción) constituyen condiciones sine qua non puede darse la acción moral. Desde este punto de vista, el deber moral irrumpe hipotéticamente guiado por unos valores adoptados por la conciencia existencial, dado que sólo ésta es moral. Tales valores se inscriben temporalmente en el pasado, y son los paradigmas una crisis ante la hermenéutica del espacio fáctico que se muestra a la conciencia como presente. La «muerte de Dios» (Gott ist tot) de Nietzsche, y la «falacia naturalista» de Hume y Moore nos impiden fundamentar categóricamente el deber moral. De ahí que sólo sea posible construirlo de modo hipotético.

Pasamos a describir algo más en detalle la «dinámica de la conciencia moral», su actividad «futurizadora». Desde sus valores (éticos, estéticos, religiosos...) anclados en el pasado, la conciencia moral «des-vela» su situacionalidad, su «ser-en-situación», su «ser-en-el-mundo». A diferencia de la epistemológica, la conciencia moral no se limita a descubrir el espacio a apercibirse de la realidad, sino que va más allá. La apercepción de la conciencia moral resulta «valorativa». No se limita a expresar qué es el mundo, sino ante todo qué debería ser, a juzgarlo. Ahí estalla la erótica, el deber, el futuro.

El deber de la conciencia moral no incumbe simplemente al mundo que «está ahí», al presente objetivo, sino que, en tanto que «existencia», ese deber me incluye a mí mismo como sujeto del «ser-en-el-mundo», de la situación. Por ello en la acción futurizadora del deber moral yo sea, a la vez, sujeto y objeto. Téngase presente, empero, que tal aserto no significa que deba reducirse a mí mismo, dado que en tal caso incurrimos en el solipsismo ético que supondría, a la vez, la negación del mismo acto y proceso moral. Ya hemos mostrado en otros lugares en detalle que en el horizonte aperceptivo del espacio se hace presente la realidad del «otro», del «tú».

Resulta ante la mirada del «tú» que me siento moralmente «comprometido». Mi «deber» sólo aparece «ante el rostro del tú», y es también ante él que soy culpable (Melich, 1989b). La «culpa» no significa el resultado de la acción moral, esto es $a$ posteriori, sino sobre todo es la estructura ontológica del mismo deber. Soy culpa- 
ble porque existo, y en tanto que «existencia» estoy obligado a escoger y renunciar. He ahí la responsabilidad moral.

Debemos ahora enlazar el análisis fenomenológico de la conciencia moral con la educación. Se tratará, pues, de elucidar qué relación tiene lugar entre la conciencia moral y la educacional (Sarramona, 1990,42), y cuál es la esencia de esta última.

\section{LA CONCIENCIA EDUCACIONAL}

Aristóteles daba inicio a su Metafísica con la conocida sentencia:

«Todos los hombres desean por naturaleza saber» (Aristóteles, 1982, I, 980a)

El «Estagirita» comprendió a la perfección una de las cualidades esenciales de la naturaleza humana: el saber. Sin embargo, de la misma tesis aristotélica puede desprenderse que todavía más allá del saber se instala el desear.

Platicar acerca del «deseo» resulta problemático, arduo y, en ocasiones, decepcionante (Fullat, 1988, 209). No ha existido ninguna filosofía que haya logrado «capturar» el deseo. Este, por su propia naturaleza, resulta esquivo a los barrotes de la razón, del logos. De ahí que nuestro discurso probablemente esté condenado irremisiblemente al fracaso. Sin embargo, en una línea socrática, intentaremos acercarnos a él, bien entendido que jamás lo lograremos satisfactoriamente.

¿Qué relación existe entre el deseo y la conciencia moral? ¿Por qué nos vemos obligados a penetrar en la naturaleza del deseo para alcanzar la esencia de la conciencia educacional? La probable respuesta es doble: por un lado es imposible fundamentar racionalmente el deber moral (Melich, 1990a), por otro, el hecho de considerar el «ek-stasis» del futuro como el propio del deber ético nos acerca al fenómeno de la «carencia» típico del desear. Veamos el primero.

A la pregunta: ¿por qué debo actuar moralmente?, no encuentro otra respuesta posible de «porque lo deseo». De nuevo se nos aparece el «Dios ha muerto» de Nietzsche.

Desde este instante deseo y deber no constituirán dos términos antagónicos, como lo han sido ordinariamente a lo largo de la historia de la filosofía moral, sino todo lo contrario. El fundamento del deber no se halla en su «saber racional» sino en un «deseo pasional». El deseo, como la conciencia, está dotado esencialmente de intencionalidad, y ahí se halla implícito el «ek-stasis» del futuro. Un fragmento de El banquete platónico lo muestra con claridad:

«Ninguno de los dioses filosofa ni desea hacerse sabio porque ya lo es, ni filosofa todo aquel que sea sabio.

\section{(...)}

Así, el que no cree estar falto de nada no siente deseo de lo que no cree necesitar» (Platón, 1979, 204 a-b).

El tópos del deseo es más arcaico que el saber. El deseo es el fundamento (Grund) de la conciencia moral. Deseo algo, incluso deseo saber, y no hay Razón que justifique en el límite la elección de mi deseo. De ahí el enlace entre deseo y pasión. El desear del deber moral se sitúa en la arracionalidad. Y es así porque precisamente es un desear «existencial» y no «trascendental». El «yo trascendental» no 
desea nada, porque no se «apasiona» por nada. El «yo trascendental» es completamente aséptico. La razón pura práctica, la del trascendental, no es moral, de ahí que jamás puede convertirse en sostén de la acción ética. Sólo la «existencia» puede hacerlo, porque sólo ella vibra apasionadamente. El deseo, entonces, se sitúa en el futuro porque es el Grund existencial del deber de la conciencia moral.

El sujeto trascendental está fuera del tiempo. La «conciencia educacional» jamás puede quedar aprisionada por el trascendental porque resulta ser, por de pronto, «conciencia moral».

Ahora bien: ¿qué aporta de novedoso la una a la otra? ¿Acaso deberíamos concluir que ambas, la conciencia moral y la educacional, son ontológicamente idénticas?

Touriñán advierte acertadamente que la conciencia educacional toma decisiones de orden técnico además de las estrictamente morales. La conciencia educacional decide moral y técnicamente. (Entiéndase, empero, que aquí el adjetivo «educacional» no está tomado en sentido restringido, sino que pretende englobar educación, formación, instrucción...).

Veámoslo en un texto significativo del profesor Touriñán:

«Decisiones morales y decisiones de educación tampoco se identifican. Desde el punto de vista de la investigación de la intervención existe la decisión técnica. (...)

En nuestra opinión, existe, en efecto, un ámbito de la educación que se identifica con el desarrollo de la dimensión moral. Desarrollar la dimensión moral es educar la decisión del hombre respecto de su propia vida y de las justificaciones de las opciones de vida. Pero incluso en esta dimensión ha de reconocerse que el conocimiento moral es un conocimiento especializado distinto del de la educación...» (Touriñán, 1989, 27-28).

En tanto que conciencia moral, la conciencia educacional es «pasión», pero en tanto que tecnología depende de la «razón». La conciencia educacional contiene a la «razón técnica». Técnica — de «tekhné»- significó para el griego un saber hacer, un saber con conocimiento de causa. Por ello también la conciencia educacional es «agónica», en el sentido etimológico de este vocablo (lucha, pugna, combate). La «agonía» de la conciencia educacional irrumpe por motivos distintos a los de la conciencia moral. En éste, recordémoslo, se daba entre los «ek-stasis» de la temporalidad; en la educacional tiene lugar por sus fundamentos (logos y pathos).

La técnica a diferencia de la tecnología (que es un discurso), es una acción. Por ello se inscribe en el mundo, en el presente, aunque sea «constituyente» porque forma parte del ámbito de la intervención.

El análisis fenomenológico nos ha aportado un nuevo eidos de la conciencia educacional: si la conciencia moral interpretaba y valoraba el presente, en tanto que técnica debe modificarlo con conocimiento de causa. Sin embargo persiste un elemento común entre ambas: la estructura temporal. Veámoslo.

En el «ek-stasis» del pasado se inscriben los valores adoptados por la conciencia moral, a los que se añaden ahora el saber tecnológico adquirido por la conciencia educacional, bien sea como resultado de su actividad como del estudio teórico. Desde este pasado, la conciencia educacional percibe e interpreta el presente, la realidad que le envuelve, que también, como en el caso de la conciencia moral, com- 
parte con el «tú» (educador/educando). La conciencia educacional realiza entonces una doble función. Como futuro se lanza hacia el deber moral que ejerce sobre sí mismo y sobre el educando. Ese deber no es otro que el deseo de alcanzar unos objetivos, proyectos o finalidades educativas. Pero, al instante, como presente, se inicia un proceso de «manipulación» del «tú», (porque de algún modo todo educar es un manipular aunque no debe entenderse este término en sentido peyorativo). Para ello la conciencia educacional se sirve de una técnica, sea cual fuere. He aquí la «agonía» entre la racionalidad de la acción técnica, por un lado, y la pasión del deseo, por otra. De ahí el enfrentamiento entre logos y pathos al que antes nos referíamos. La conciencia educacional forma parte de la conciencia moral, pero no se confunde con ella. La tekhné es un nuevo elemento que se ubica temporalmente en el «pasado», junto a los valores, y permite al sujeto «manipular» y cambiar la realidad, el presente, el espacio dado, y al «otro» como «congénere» (Schutz 1972)( que «interacciona» conmigo en este espacio.

La conciencia educacional es ontológicamente fracaso por la misma razón que lo es la «existencia» (Melich, 1900), esto es: por no poder asir las finalidades que se ha propuesto. Por este motivo, por ser ontológicamente deseo, la conciencia educacional será siempre una conciencia «carente», incompleta, insatisfecha y fracasada. Escribe Paul Ricoeur:

«El deseo es, en efecto, falta de..., impulso hacia...»(Ricoeur, 1969, 73)

Solamente desea el que carece. Si la conciencia moral quedase satisfecha fenecería y, por lo mismo, con su óbito llegaría también el de la «existencia», porque «existir» es sinónimo de «educación». La educación, como la filosofía es «ser en camino »(Jospers, 1983, 13). La educación es un «ir a la búsqueda de un horizonte inalcanzable». Las metas pedagógicas, como las preguntas filosóficas, son momentos de un avanzar incesante, de un deseo tan largo como la propia existencia. Jamás llegamos a alcanzar toda la verdad. Nada de cuanto se puede aprender, como ha puesto de manifiesto Karl Jaspers, es absoluto. Entiéndase bien: no se trata de optar por un escepticismo, sino tan sólo de dejar en sus puras carnes el drama antropológico, moral y educativo de la existencia humana. Se impone aceptar la modestia de conocimiento.

Para llegar a «aprender» es necesario «aprehender», fagocitar, devorar, anhelar, apasionarse. Todo deseo, en tanto que futuro, irrumpe con una pregunta. Ya lo mostramos al inicio de nuestro trabajo. Ahí, en la pregunta, juega un papel fundamental la curiosidad. Esta, a su vez, se motiva preguntando.

Vivimos en un tiempo de crisis axiológica, donde nada es cierto, y sin embargo el educador es contundente en sus respuestas. He ahí una enorme paradoja pedagógica de nuestra civilización. Habitamos en una historia en la que todo se ha relativizado, y sin embargo maestros y padres hacen gala de afirmaciones absolutas. Avanzamos en un mundo en el que se ha perdido el norte, en el que se ha borrado el horizonte (por utilizar una metáfora de Nietzsche), en el que las coordenadas morales se han resquebrajado, y sin embargo el pedagogo sabe perfectamente qué es lo bueno, lo cierto y lo correcto. El docente habla, expone, explica. El discente escuha, copia, memoriza, repite. No hay lugar al interrogante, la duda está penalizada. El deseo ha muerto a manos del orden, de la razón, de lo fijo, de lo acabado, de lo 
demostrado científicamente. El saber ha aniquilado al desear, y el futuro ha fallecido a manos del presente y, sobre todo, del pasado.

\section{BIBLIOGRAFIA}

ARISTÓTELES (1982): Metafísica, Gredos, Madrid.

BRENTANO, F. (1935): Psicología, Revista de Occidente, Madrid.

BRENTANO, F. (1927): El origen del conocimiento moral, Revista de Occidente, Madrid.

BOLLNOW, O. F. (1969): Hombre y espacio, Labor, Barcelona.

DANNER, H. (1979): Methodem geisteswissenschaftlicher Pädagogik, Reinhardt, UTB, München-Basel.

DERVOLAV, J. (1989): «Gewissen: eine pädagogische Kategorie», Pädagogische Rundschau, núm. 4, Frankfurt.

FREIRE, P. (1978): Pedagogía y acción liberadora, Zero, Madrid.

FULlAT, O. (1988): La peregrinación del mal, U. A. B., (Bellaterra) Barcelona.

GURWITSCH, A. (1979): El campo de la conciencia. Un análisis fenomenológico, Alianza Ed., Madrid.

HEIDEGGER, M. (1978): Wegmarken, Klostermann, Frankfurt.

HEIDEGGER, M. (1979): Sein und Zeit, Niemeyer, Tübingen.

HEIDEGGER, M. (1980): Holzwege, Klostermann, Frankfurt.

HUSSERL, E. (1959): Fenomenología de la conciencia del tiempo inmanente, Nova, Buenos Aires.

HUSSERL, E. (1977): Cartesianische Meditationen, Meiner, Hamburg.

HUSSERL, E. (1980): Ideen zu einer reinen Phänomenologie und phänomenologischen Philosophie, Niemeyer. Tübingen.

JASPERS, K. (1973): Philosophie, Springer, Heidelberg.

JASPERS, K. (1983): Einführung in die Philosophie, Piper, München.

JENDROWIAK, H. W. (1989): «Zur Theorie der pädagogischen Verantwortung», Pädagogische Rundschau, núm. 4, Frankfurt.

KANT, I. (1974): Kritik der praktischen Vernunft, STW, Frankfurt.

KANT, I. (1982): Kritik der reinen Vernunft, STW, Frankfurt.

LASSAHN, R. (1989): «Erziehung und moralisches Bewußtsein», Pädagogische Rundschau, núm. 4, Frankfurt.

MELICH, J. C. (1989a): Situaciones-límite y educación. Estudio sobre el problema de las finalidades educativas, P. P. U., Barcelona.

MELICH, J. C. (1989b): «La estructura esencial de la educación moral. Un análisis fenomenológico», Revista de Ciencias de la Educación, núm, 139, Madrid.

MELICH, J. C. (1989c): «El extraño y el cómplice», en AA.VV., Hombre y educación, P. P. U., Barcelona.

MELICH, J. C. (1990a): «Sobre el problema de considerar la razón como fundamento de la educación moral» Filosofía de la educación, hoy, Vol. II, Madrid.

MELICH, J. C. (1990b): «El método fenomenológico y la filosofía de la educación», Bordón, Madrid.

MELICH, J. C. (1990c): «L'educació socrática: una proposta actual», Qüestions de vida cristiana, núm. 150-151, Montserrat (Barcelona).

PÖGGELER, O. (1986): El camino del pensar de Martin Heidegger, Alianza, Madrid.

PLATÓN, (1979): Obras completas, Aguilar, Madrid. 
REBOUL, 0. (1981): El adoctrinamiento, El Ateneo, Buenos Aires.

RESWEBER, J. P. (1986): Les pédagogies nouvelles, PUF, París.

RICOEUR, P. (1969): Finitud y culpabilidad, Taurus, Madrid.

SARRAMONA, J. (1990): Tecnología educativa (Una valoración crítica), CEAC, Barcelona.

SARTRE, J. P. (1973): «Une idée fondamentale de la phénoménologie de Husserl: l'intentionalité», Situations I, Gallimard, París.

SARTRE, J. P. (1988): L'être et le néant, Gallimard, París.

SCHELER, M. (1935): Sociología del saber, Revista de Occidente, Madrid.

SCHÜTZ, A. (1972): Fenomenología del mundo social, Paidós, Buenos Aires.

TOURIÑÁN, J. M. (1989): «Las finalidades de la educación. Análisis teórico», en ESTEVE, J. M. (ed.), Objetivos y contenidos de la educación para los años noventa, Universidad de Málaga.

UNAMUNO, M. (1982): Del sentimiento trágico de la vida, Austral, Madrid.

ZUBIRI, X. (1986): Sobre el hombre, Alianza, Madrid. 